\title{
AOR
}

Selected Papers of \#AolR2021:

The 22nd Annual Conference of the

Association of Internet Researchers Virtual Event / 13-16 Oct 2021

\section{POLITCAL GAMES IN VIRTUAL HONG KONG}

\author{
Hugh Davies \\ RMIT University

\section{Hong Kong in videogames}

Following Akbar Abbas's seminal 1997 study Hong Kong: Culture and the Politics of Disappearance, this paper argues that just as Hong Kong is disappearing in the real world, it is re-appearing in the virtual world of videogames. With attention to the 2019 protests in the city of Hong Kong, this paper reviews media reportage, academic scholarship and explores virtual game spaces to examine how videogames and other digital platforms came to enact, elaborate and represent the 2019 activist movement. Discussing a number of videogames that were specifically developed as objects of protest such as Liberate Hong Kong (2019), Revolution in Our Time (2019), and Add Oil (2019), this paper also considers the ways in which existing digital games such as GTAV (2013), Pokémon GO (2016), Animal Crossing: New Horizons (2020) as well as digital platforms such as Twitch, Airdrop, and Uber were tactically deployed as sites of protest by Hong Kong activists.

\section{Protest and Play}

Throughout 2019 , Hong Kong was a city of protest. The unrest began enthusiastically but peacefully, with activists staging large demonstrations. As the year wore on, clashes between police and protesters became increasingly violent, with officers firing live bullets and activists responding with barricades and petrol bombs. At the height of the violence between police and protesters, Hong Kong's physical streets came to resemble a battlefield more familiar to the virtual realm of videogames than the actual urban landscape of Hong Kong, signalling a broader slippage between physical world and videogame that was noted by several media outlets. Videogames were being deployed aesthetically, virtually and conceptually as protest instruments. Ming-sho Ho (2020) notes that collective learnings from 2014 Umbrella Revolution enabled Hong Kong's 2019 anti-extradition movement to launch more challenging protest five years later, with participants recognising the need for more distributed protests, decentralized decision making and radical experimentation. Videogames emerged as their centrepiece of innovative and experimental protest. 
Simultaneous to the fierce street skirmishes in Hong Kong streets, another domain of battle was occurring behind computer screens, smart phones and across digitally networked spaces. Lacking formal or centralised leadership, Hong Kong activists structured their activities in social media and game spaces, using these digital platforms to recruit new participants, to plan and enact protest events, and to advance their activist agenda. Digital services as WhatsApp, Line, LIHKG, Twitter and Telegram surged with agitprop memes while strategies and tactics for the next demonstration were proposed. Suggestions were voted up or down on social media in a kind of gamified ad-hoc democratic approach. Services such as Airdrop, Tinder, Uber, Firechat became adapted as ways for activists to organise and assemble (Ting, 2020).

The utilisation of games and play in the protests received significant media and scholarly attention. Hanna Wirman and Rhys Jones (2020) document the deployment of analogue play and game structures in the 2019 Hong Kong protesters while Hugh Davies (2020a; 2020b) explores the extensive use of videogame spaces, rhetoric's platforms and popularity among the anti-extradition movement. Yue-Jin Ho (2020) identifies videogame lexicon and aspects of gamification in the protests. In previous scholarship, the deployment of videogames and play as methods, modes and sites of protest had been foreshadowed, but had never been seen at this scale. In a chapter titled Saving Worlds with Videogame Activism, Robert Jones (2007) discussed videogames as an inherently spatial medium possessing the potential to open up new political spaces, while Dean Chan (2009) had identified videogames in China as constitutive of new fields of struggle. In 2019, HongKongers were attempting to save their city from what they saw as an encroachment from Mainland China.

By 2020, the streets of Hong Kong were all but abandoned. The withdrawal was due to a combination of the COVID-19 pandemic as well as the newly enacted security law that saw frantic attempts by many Hong Kong citizens to scrub their digital footprints clean (Gilbert, 2020). These restrictions imposed on physical spaces forced increasingly more activists to make an 'exodus to the virtual' in Castronova's terms (2008) in order to enact their grievances. With protest now impossible and pro-democratic political slogans illegal, Hong Kong as an independent and free entity has all but disappeared in the physical world, but increasingly exists in the domain of videogames.

\section{Methodology}

With the contested politics of Hong Kong playing out in virtual worlds, this paper draws extensively on digital ethnography undertaken during 2019 and 2020 within the digital spaces in which protest activities took place. These findings have been augmented with scholarship on digital games and virtual spaces as activist platforms that appeared in the years prior to the Hong Kong protests, as well as in response to the events of 2019. With digital platforms becoming key to activist and independence movements globally, this paper explores how videogames are solidifying not only as sites of protest and activism, but also as virtual destinations for diasporas of political refugees whose homelands have been lost in the physical world. 


\section{References}

Abbas, Akbar. (1997). Hong Kong: Culture and the Politics of Disappearance. Minneapolis: University of Minnesota Press.

Castronova, Edward. (2008). Exodus to the Virtual World: How Online Fun Is Changing Reality. St. Martin's Press.

Chan, Dean. (2009). Beyond the 'Great Firewall': The case of in-game protests in China. In L. Hjorth \& D. Chan (Eds.), Gaming cultures and place in Asia-Pacific (pp. 141-157). New York, NY: Routledge.

Davies, Hugh. (2020a). Hong Kong and Insect Rhetoric: The Spatial Politics of Pokémon GO. In DiGRA '20 - proceedings of Digital Games and Research Association: Play Everywhere. Tampere, Finland.

Davies, Hugh. (2020b). Spatial Politics at Play: Hong Kong Protests and Videogame Activism. In Proceedings of the 2020 DiGRAA Australia Conference, Brisbane Queensland, Australia.

Gilbert, David. (2020). Hong Kong Residents Are Erasing Their Own Internet Histories Before China's Big Crackdown. Vice. https://www.vice.com/en/article/qj4k95/hong-kongresidents-are-erasing-their-own-internet-histories-before-chinas-big-crackdown

Ho, Ming-sho. (2020). How Protests Evolve: Hong Kong's Anti Extradition Movement and Lessons Learned From the Umbrella Movement. Mobilization: An International Quarterly 1 September 2020; 25 (SI): 711-728. doi: https://doi.org/10.17813/1086$\underline{671 X-25-5-711}$

Ho, Yue-Jin. (2020). Game Lexicon and Gamification in the Hong Kong Protest. 2020. In DiGRA '20 - proceedings of Digital Games and Research Association: Play Everywhere. Tampere, Finland.

Jones, Robert. 2009. Saving Worlds with Videogame Activism, Handbook of Research on Effective Electronic Gaming in Education. New York University, USA.

Ting, Tin-yuet. (2020). From 'be water' to 'be fire': nascent smart mob and networked protests in Hong Kong, Social Movement Studies, 19:3, 362 368, DOI: $10.1080 / 14742837.2020 .1727736$

Wirman, Hanna., Jones, Rhys. (2020). Block the Spawn Point: Play and Games in the Hong Kong 2019 Pro-democracy Protests. In DiGRA '20 - proceedings of Digital Games and Research Association: Play Everywhere. Tampere, Finland. 